\title{
Evaluation of two concepts of fertilization for wheat in a calcareous soil of Bangladesh
}

\begin{abstract}
Two popular concepts of soil fertilization, basic cation saturation ratio (BCSR) and sufficiency level of available nutrients (SLAN), were tested on a calcareous soil (Aeric haplaquept) during 1995-1996 at the Bangladesh Rice Research Institute (BRRI) Regional Station Rajshahi using wheat as a test crop. According to BCSR concept the soil was deficient in potassium $(\mathrm{K})$ and according to SLAN concept it was deficient in phosphorus $(\mathrm{P})$, respectively. Potassium dose of $120 \mathrm{~kg}$ ha-1 [to attain $2 \%$ saturation of total cation exchange capacity (CEC) according to BCSR] along with other two doses (0 and $60 \mathrm{~kg} \mathrm{~K}$ ha-1) and P dose of $50 \mathrm{~kg}$ ha-1 (to attain available $\mathrm{P}$ at sufficiency level) along with other two doses (0 and $100 \mathrm{~kg}$ P ha-1) were compared in a randomized complete block design. The application of $50 \mathrm{~kg} \mathrm{P}$ ha-1 significantly increased plant height, spikes $\mathrm{m}-2$, grains per spike, grain and straw yields of wheat over $0 \mathrm{~kg} \mathrm{P}$ ha- 1 with or without $\mathrm{K}$ but increasing $\mathrm{P}$ dose from 50 to $100 \mathrm{~kg}$ P ha-1 did not give additional yields. The agronomic parameters and yields were not affected significantly by K application. Similar results were also observed in nutrient content and nutrient uptake. Thus, SLAN concept appeared as an effective tool for fertilizer recommendation for the calcareous soil while BCSR gave no apparent result there.
\end{abstract}

Keyword: Fertilization; Calcareous soil; Wheat 